\title{
Novel Antibiotic Testing Approaches Reveal Reduced Antibiotic Efficacy Against Shiga Toxin-Producing Escherichia coli 0157:H7 Under Simulated Microgravity
}

\author{
Hye Won Kim and Min Suk Rhee* \\ Department of Biotechnology, College of Life Sciences and Biotechnology, Korea University, Seoul, South Korea
}

\section{OPEN ACCESS}

Edited by: Kunihiko Nishino,

Osaka University, Japan

Reviewed by:

Steven Ripp,

The University of Tennessee, Knoxville, United States

Rustam Aminov,

University of Aberdeen,

United Kingdom

*Correspondence:

Min Suk Rhee

rheems@korea.ac.kr

Specialty section:

This article was submitted to Antimicrobials, Resistance

and Chemotherapy,

a section of the journal

Frontiers in Microbiology

Received: 31 July 2018 Accepted: 11 December 2018 Published: 21 December 2018

Citation:

Kim HW and Rhee MS (2018) Novel Antibiotic Testing Approaches Reveal Reduced Antibiotic Efficacy Against Shiga Toxin-Producing Escherichia coli 0157:H7 Under

Simulated Microgravity.

Front. Microbiol. 9:3214.

doi: 10.3389/fmicb.2018.03214
As a foodborne and environmental pathogen, Shiga toxin-producing Escherichia coli O157:H7 could pose a health threat to immunocompromised astronauts during a space mission. In this study, novel approaches, including real-time testing and direct evaluation of resistance mechanisms, were used to evaluate antibiotic efficacy against $E$. coli 0157:H7 under low-shear modeled microgravity (LSMMG) produced using a rotary cell culture system. When compared with normal gravity (NG), bacterial growth was increased under LSMMG in the presence of sub-inhibitory nalidixic acid concentrations and there was an accompanying up-regulation of stress-related genes. LSMMG also induced transcriptional changes of the virulence genes stx 1 and stx2, highlighting the potential risk of inappropriate antibiotic use during a spaceflight. The degree of bacterial cell damage induced by the antibiotics was reduced under LSMMG, suggesting low induction of reactive oxygen species. Efflux pumps were also shown to play an important role in these responses. Increased cell filamentation was observed under LSMMG upon ampicillin treatment, possibly reflecting a protective mechanism against exposure to antibiotics. These observations indicate that, in the presence of antibiotics, the survival of $E$. coli $\mathrm{O} 157: \mathrm{H} 7$ is greater under LSMMG than under NG, indicating that antibiotic therapies may need to be adjusted during space missions.

Keywords: Escherichia coli 0157:H7, space environment, antibiotic test, Shiga toxin gene, cellular mechanism

\section{INTRODUCTION}

On-board infections are of concern to those seeking to promote manned space exploration (Taylor and Sommer, 2005). Increased bacterial capacity to cause disease (Wilson et al., 2007; Crabbé et al., 2011) and the weakening of the immune system in space (Crucian et al., 2008), especially, could give rise to conditions favoring bacterial infections. Indeed, evidence exists for urinary tract infections among the crew of the Apollo 13 spaceflight mission (Taylor, 1974), and in-flight crosscontamination of the upper respiratory tract (Decelle and Taylor, 1976), conjunctivitis, and acute respiratory and dental infections among astronauts living on the Russian space station Mir (Ball and Evans, 2001). The transmission of antibiotic-resistant strains from one astronaut to another on the Soviet and International Space Stations has also been reported (Ilyin, 2005). 
As incidents of bacterial infections and the transfer of antibiotic-resistant bacteria in space have been documented, the susceptibility of bacteria to antibiotics under microgravity conditions has been studied for several decades. Increased bacterial resistance to antibiotics has been reported by various researchers (Tixador et al., 1985a; Lapchine et al., 1986; Juergensmeyer et al., 1999) and evidence exists for the reduction of bioavailability of orally-administered drugs in space (Tietze and Putcha, 1994). The major causes of these responses are, however, not yet clear. Therefore, clarification of the efficacy of antibiotics in space or a space-like environment is a critical issue that needs to be carefully considered.

Investigations into the effect of microgravity on microorganisms during real spaceflight are limited by flight opportunities, financial costs, the need for specialized equipment in the spacecraft or space station, and astronauts' time (Nickerson et al., 2004). As an alternative, a ground-based spaceflight analog bioreactor, the High-Aspect Ratio Vessel (HARV; Synthecon, Houston, TX, United States), was developed at the Johnson Space Center/National Aeronautics and Space Administration. It produces a low-shear microgravity environment similar to that found in space. The simulated low gravity environment is generated by the rotation of the HARV, which continuously maintains the gravitational vector experienced by the bacterial cells to near-zero (Valluri and Gonda, 2006).

In the current study, an attempt was made to assess antibiotic efficacy under simulated microgravity, typical of the space environment, against a pathogenic bacterium of significant public health impact, Escherichia coli O157:H7. This is a foodborne and environmental pathogen that can cause life-threatening human disease even when only a small number of cells are consumed (Phillips, 1999). Antibiotic-resistant strains of this serotype pose a risk to food safety and public health (Schroeder et al., 2002). E. coli $\mathrm{O} 157: \mathrm{H} 7$ strains can produce one or both of the two types of Shiga toxin (Stx1 and Stx2) encoded by the stx genes. The use of antibiotics to treat infections may lead to unexpected side effects such as Shiga toxin induction (Kimmitt et al., 2000). The strain studied here, ATCC 43895, was originally isolated from ground beef linked to a large outbreak in the United States in 1982 (Riley et al., 1983) and harbors both stx1 and stx2 (Bürk et al., 2003).

The main goals of this study were to determine the efficacy of antibiotics that target different biological molecules [ampicillin (AM) targeting peptidoglycan, gentamicin (GM) targeting the ribosome, and nalidixic acid (NA) targeting DNA] against E. coli O157:H7 under simulated microgravity using novel approaches overcoming the limits of conventional antibiotic susceptibility testing, and to determine the mechanisms responsible for resistance. Growth-monitoring and inactivation assays were conducted since they reveal the response of bacteria under simulated microgravity over time. Cellular responses to antibiotics and the effects of antibiotic treatments were evaluated on the basis of (i) molecular genetic analysis of the antibiotic stress response $(r p o S, o x y R$, and soxR) (Lushchak, 2001; Matin, 2009) and virulence-related genes (stx1 and stx2), (ii) flow cytometry analysis of cell damage (Saint-Ruf et al., 2016), (iii) an efflux accumulation assay using ethidium bromide (EtBr), a common substrate of efflux pumps of the Enterobacteriaceae
(Schumacher et al., 2007), and (iv) direct observation of morphological changes by microscopy.

\section{MATERIALS AND METHODS}

\section{Bacterial Strains and Growth Media}

All studies were performed using E. coli O157:H7 ATCC 43895 from the American Type Culture Collection. This isolate, also referred to as CDC EDL933, was originally isolated from ground beef linked to a large outbreak of foodborne disease in the United States in 1982 (Riley et al., 1983), and it harbors the stx 1 and stx 2 genes (Bürk et al., 2003). Bacterial cells were stored at $-80^{\circ} \mathrm{C}$ in a medium containing $20 \%$ glycerol. When required, the cells were grown overnight in Muller-Hinton ( $\mathrm{MH})$ broth (Difco, Sparks, MD, United States) at $37^{\circ} \mathrm{C}$ in a shaking incubator set at $225 \mathrm{rpm}$ (VS-8480S, Vision Scientific, Co., Ltd., Seoul, South Korea). The initial optical density at $660 \mathrm{~nm}$ of stationary phase cultures was measured using a SmartSpec ${ }^{\mathrm{TM}}$ Plus spectrophotometer (Bio-Rad, Hercules, CA, United States).

\section{Equipment Used for LSMMG and NG Experiments}

The Rotary Cell Culture System ${ }^{\mathrm{TM}}$ (RCCS ${ }^{\mathrm{TM}}$; Synthecon) and a $50 \mathrm{ml} \mathrm{HARV} \mathrm{(Synthecon)} \mathrm{were} \mathrm{used} \mathrm{to} \mathrm{generate} \mathrm{low-shear}$ modeled microgravity (LSMMG, spaceflight analog conditions) and normal gravity (NG, Earth conditions) in the laboratory, as described in previous studies (Kim et al., 2014; Kim and Rhee, 2016). The HARV apparatus was filled with the appropriate overnight cultures, with zero headspace and no bubbles, and maintained in a constant state of suspension. The vessels were rotated at $25 \mathrm{rpm}$ around a horizontal axis for LSMMG, with the hydrodynamic forces, including centrifugal, Coriolis, and shear forces, offsetting the gravitational force in the bioreactor. The counterpart NG conditions were obtained by rotating the vessels around a vertical axis. All incubations were performed at $37^{\circ} \mathrm{C}$, and a gas-permeable membrane on the back of HARV allowed air exchange during incubation.

\section{Susceptibility Testing by the Disk Diffusion Method}

Antibiotic susceptibility was tested by the disk diffusion method according to the recommendations of the Clinical and Laboratory Standards Institute (CLSI, 2012). The surface of $\mathrm{MH}$ agar (Difco) was inoculated with a swab dipped in the cell suspension with a turbidity adjusted to $0.5 \mathrm{McF}$ arland standard. Commercial antibiotic susceptibility disks (Oxoid, Basingstoke, United Kingdom), including AM (10 $\mu \mathrm{g}), \mathrm{GM}(10 \mu \mathrm{g})$, and NA $(30 \mu \mathrm{g})$, were placed onto the surfaces of the inoculated plates and the plates were then incubated at $37^{\circ} \mathrm{C}$ for $18 \mathrm{~h}$. The diameter of the inhibition zone was measured and the antibiotic susceptibility was classified as resistant (R), intermediate (I), or susceptible (S), based on the manufacturer's instructions. All experiments were repeated six times. 


\section{MIC Determination by the Broth Microdilution Assay}

Antibiotic solutions (Sigma-Aldrich, St. Louis, MO, United States) were freshly prepared before each experiment. The minimum inhibitory concentration (MIC) values for E. coli O157:H7 cells cultured under LSMMG and NG were determined by the method currently recommended by CLSI (Watts et al., 2008) in sterile, 96-well, U-bottomed plates. Briefly, each microdilution well-containing $100 \mu \mathrm{l}$ of the corresponding twofold antibiotic dilution was inoculated with $100 \mu \mathrm{l}$ of a cell suspension (final concentrations of ca. $5.0 \times 10^{5} \mathrm{CFU} / \mathrm{ml}$ ). The microdilution trays were incubated at $37^{\circ} \mathrm{C}$ for $18 \mathrm{~h}$, and the MIC was defined as the lowest concentration of antibiotic for which no visible cell growth was observed. In each case, cell suspensions inoculated in the absence of antibiotics served as the positive control. The MIC values determined (Table 1) were used to calculate antibiotic concentrations corresponding to $1 / 2 \times$ MIC and $4 \times$ MIC. All experiments were repeated in triplicate.

\section{Growth Kinetics at Sub-inhibitory Antimicrobial Concentrations}

Overnight cultures were diluted in MH broth supplemented with sub-inhibitory concentrations of each antibiotic $(1 / 2 \times \mathrm{MIC})$ and then incubated under LSMMG or NG, as described above. A sterile $5 \mathrm{ml}$ syringe was used to remove $500 \mu \mathrm{l}$ samples through a port on the front plate of the HARV after $0,3,6,12,24$, and $48 \mathrm{~h}$ of incubation. The zero headspace within the HARV was maintained by adding an equivalent volume of sterile $0.85 \%$ saline. Bacterial growth was monitored by measuring the $\mathrm{OD}_{600}$ (Bio-Rad). The numbers of viable cells were determined using the plate-counting method. Briefly, the cells were serially diluted 10fold in sterile $0.85 \%$ saline and spread-plated onto $\mathrm{MH}$ agar, and the colonies were counted after incubation at $37^{\circ} \mathrm{C}$ for $24 \mathrm{~h}$. All experiments were repeated at least six times.

\section{RNA Extraction and cDNA Synthesis}

Total RNA was extracted from cells that had been cultured in the MH broth for $24 \mathrm{~h}$ under LSMMG and NG using TRIzol ${ }^{\circledR}$ (Invitrogen, Grand Island, NY, United States), following the manufacturer's instructions. The concentration of total RNA was determined using an ND-1000 spectrophotometer (NanoDrop Technologies, Wilmington, DE, United States). The quality of RNA in a sample was deemed to be acceptable if the $A_{260 / 280}$ ratio was 1.9-2.1. The sample RNA was reverse-transcribed using the high-capacity cDNA reverse transcription kit (Applied Biosystems, Foster City, CA, United States) according to the manufacturer's instructions. Briefly, $2.0 \mu \mathrm{g}$ RNA was reversetranscribed in a reaction containing $10 \times$ random primers, $25 \times$ dNTP mix $(100 \mathrm{mM}), 10 \times$ buffer, $1.0 \mu$ l MultiScribe ${ }^{\text {TM }}$ reverse transcriptase, and $1.0 \mu \mathrm{l}$ RNase inhibitor, with a total reaction volume of $20 \mu \mathrm{l}$. cDNA synthesis was performed in a thermo-cycler (Thermo Fisher Scientific, Rockford, IL, United States) with the following cycling conditions: $25^{\circ} \mathrm{C}$ for $10 \mathrm{~min}, 37^{\circ} \mathrm{C}$ for $120 \mathrm{~min}$, and $85^{\circ} \mathrm{C}$ for $5 \mathrm{~min}$, followed by $4^{\circ} \mathrm{C}$ to stop the reaction.

\section{qRT-PCR for the Determination of the Stress and Virulence-Related Gene Expression}

The expression of stress- (rpoS, oxyR, and soxR) and virulence(stx1 and stx2) related genes in E. coli $\mathrm{O} 157: \mathrm{H} 7$ in response to the simulated microgravity was evaluated using qRT-PCR (primer sequences are given in Supplementary Table S1). Each $25 \mu \mathrm{l}$ reaction contained $2 \mu \mathrm{l}$ reverse-transcribed cDNA, $12.5 \mu \mathrm{l}$ Maxima SYBR Green/ROX qPCR master mix (Thermo Scientific, Hampton, NH, United States), $0.2 \mu \mathrm{M}$ of each primer, and $5.5 \mu \mathrm{l}$ nuclease-free water. The Maxima SYBR Green/ROX qPCR master mix contained the following components: Maxima ${ }^{\circledR}$ Hot Start Taq DNA polymerase, dNTPs, SYBR ${ }^{\circledR}$ Green I dye, ROX passive reference dye, and optimized PCR buffer. The qRT-PCR was carried out using a Bio-Rad iQ5 thermal cycler (Bio-Rad), with the following conditions: pretreatment at $50^{\circ} \mathrm{C}$ for $2 \mathrm{~min}$; an initial denaturation at $95^{\circ} \mathrm{C}$ for $10 \mathrm{~min}$; and 40 cycles of denaturation, annealing, and extension, i.e., $95^{\circ} \mathrm{C}$ for $15 \mathrm{~s}, 63^{\circ} \mathrm{C}$ for $1 \mathrm{~min}$, and $72^{\circ} \mathrm{C}$ for $30 \mathrm{~s}$, respectively. The fluorescence data were collected at the end of each cycle. No template controls were included and consistently no Ct values were obtained for any of the negative controls (data not shown). The relative

TABLE 1 | The susceptibility and Minimum Inhibitory Concentrations (MIC) of the tested antibiotics against E. coli O157:H7 ATCC 43895 cultured under LSMMG and NG in $\mathrm{MH}$ broth for $24 \mathrm{~h}$.

\begin{tabular}{|c|c|c|c|c|c|c|c|}
\hline \multirow[t]{2}{*}{$\begin{array}{l}\text { Biological } \\
\text { effect }\end{array}$} & \multirow[t]{2}{*}{ Class } & \multirow[t]{2}{*}{ Antibiotic } & \multirow[t]{2}{*}{ Primary target } & \multicolumn{2}{|c|}{$\begin{array}{l}\text { Diameter of inhibition zone, } \\
\mathrm{mm} \text { (antibiotic susceptibility) }\end{array}$} & \multicolumn{2}{|c|}{ MIC (mg/L) } \\
\hline & & & & LSMMG & NG & LSMMG & NG \\
\hline $\begin{array}{l}\text { Protein } \\
\text { synthesis } \\
\text { inhibitor }\end{array}$ & Aminoglycoside & Gentamycin (GM) & $\begin{array}{l}30 S^{a} \text { ribosomal } \\
\text { subunit }\end{array}$ & $21.8 \pm 1.3(\mathrm{~S})$ & $21.5 \pm 1.7(\mathrm{~S})$ & 0.5 & 0.5 \\
\hline $\begin{array}{l}\text { DNA synthesis } \\
\text { inhibitor }\end{array}$ & Quinolone & Nalidixic acid (NA) & $\begin{array}{l}\text { Topoisomerase II } \\
\text { Topoisomerase IV }\end{array}$ & $22.8 \pm 0.5(S)$ & $22.8 \pm 1.9(\mathrm{~S})$ & 4.0 & 4.0 \\
\hline
\end{tabular}

Mean $\pm S D ; n=6$ per group; ${ }^{a} S=A$ svedgerg unit; ${ }^{b} S=$ susceptible. 
gene expression was determined using the comparative critical threshold $\left(2^{-\Delta \Delta C T}\right)$ method (Schmittgen and Livak, 2008). The expression of the glyceraldehyde-3-phosphate dehydrogenase (GAPDH) gene was used to normalize the input amounts of RNA and the expression of the target genes was then determined. All experiments were conducted six times.

\section{Time-Kill Studies}

Fresh $\mathrm{MH}$ broth containing antibiotic concentrations corresponding to $4 \times \mathrm{MIC}$ was inoculated with an overnight culture (final cell density of ca. $5 \times 10^{5} \mathrm{CFU} / \mathrm{ml}$ ) and incubated under LSMMG and NG, as described above. Samples were removed through the port in the HARV over the course of $48 \mathrm{~h}$ $(0,3,6,12,24$, and $48 \mathrm{~h})$. The zero headspace was maintained, and the cell viability was determined as described above. Control samples containing $\mathrm{MH}$ broth with no antibiotics were prepared and tested in the same way. All experiments were repeated six times.

\section{Flow Cytometry}

For the flow cytometry analysis, $24 \mathrm{~h}$ LSMMG and NG cultures grown in the presence of $4 \times$ MIC of each antibiotic were diluted or concentrated to obtain $10^{7}$ cells $/ \mathrm{ml}$ in filtered (pore size, $0.22 \mu \mathrm{m}$ ) phosphate-buffered saline (PBS). The cells were washed twice and diluted in PBS supplemented with $2 \mathrm{mg} / \mathrm{L}$ AFH (absorption: $630 \mathrm{~nm}$, emission: $645 \mathrm{~nm}$; Invitrogen, Carlsbad, CA, United States). They were then incubated at room temperature for $15 \mathrm{~min}$ in the dark, and washed with PBS before analysis.

Flow cytometry analysis was performed using a FACS Caliber flow cytometer (Becton Dickinson Biosciences, San Jose, CA, United States) with an excitation wavelength of $635 \mathrm{~nm}$ (the red diode). An FSC/SSC (side scattered light) diagram was used for gating to define the target bacterial cells. The data were analyzed using the BD CellQuest Pro software (Becton Dickinson Biosciences). An appropriate optical filter (FL4) was used to measure the fluorescence emitted by AFH. The signals were detected by a photodiode detector with a forward scatter voltage setting of E02, and 10,000 events were collected for each sample. The acquired events were presented as a histogram, with the M1 region set using live and dead cells, and the percentage of cells in the $\mathrm{M} 1$ region was then calculated.

\section{Modified EtBr Accumulation Assay}

Accumulation of EtBr was evaluated as described previously (Smith and Blair, 2013), with the following modifications to determine the effect of LSMMG over a longer incubation period of at least $24 \mathrm{~h}$. The cultures were grown to an $\mathrm{OD}_{600}$ of 0.6 (mid-exponential phase) and then washed three times with PBS. For optimum efflux conditions, glucose was added to a final concentration of $0.4 \%$ in $\mathrm{PBS}$, and, where it was required to negate the efflux of EtBr in the absence of glucose, $100 \mu \mathrm{M}$ carbonyl cyanide m-chlorophenylhydrazone (CCCP) was used. Thereafter, EtBr was added to a final concentration of $5 \mu \mathrm{g} / \mathrm{ml}$ and the bacterial cultures were incubated at $37^{\circ} \mathrm{C}$ (optimum) and $25^{\circ} \mathrm{C}$ (no activation) for $24 \mathrm{~h}$ in the HARV-RCCS, as described above. Following incubation, $200 \mu$ l of each culture was transferred to the wells of a black microtiter tray (Thermo Fisher Scientific, Rochester, NY, United States) and sample fluorescence was determined at the excitation and emission wavelengths of 535 and $620 \mathrm{~nm}$, respectively, using a Hidex Sense plate reader (HIDEX, Turku, Finland). The measurements were recorded at least six times.

\section{Phase-Contrast Microscopy}

Microscopic observations were conducted using samples grown for $24 \mathrm{~h}$ in broth containing $4 \times$ MICs of antibiotics. After centrifugation $\left(3000 \times g\right.$ for $15 \mathrm{~min}$ at $\left.4^{\circ} \mathrm{C}\right)(\mathrm{MF} 80$, Hanil Science Industrial, Co., Ltd., Gangneung, South Korea), the pellet was resuspended in PBS and $5 \mu$ l of the cell suspension was deposited onto a glass slide to be observed using phasecontrast microscopy (Leica DM6000, Leica Microsystems GmbH, Mannheim, Germany). Images were captured using a Leica DFC360 FX camera. Dimensions of each bacterial cell $(n=30$ per group with cells randomly selected from 10 different fields of view) were measured by ImageJ software (U.S. National Institutes of Health, Bethesda, MD; United States ${ }^{1}$ ) and normalized according to the cell length $(\mu \mathrm{m})$.

\section{Statistical Analysis}

Statistical analysis was performed using SAS version 9.4 (SAS Institute, Inc., Cary, NC, United States). The data were evaluated using a general linear model for variance analysis. Tukey's $t$-test was used to determine the significance of the differences in bacterial survival in E. coli O157:H7 cultures incubated under LSMMG and NG.

\section{RESULTS}

\section{Conventional Antibiotic Susceptibility Testing}

The susceptibility of E. coli O157:H7 ATCC 43895 cultivated under LSMMG (spaceflight analog conditions) and NG (Earth conditions) was first assessed against different antibiotics using the disk diffusion method (Figure 1 and Table 1). A comparison of bacterial antibiotic susceptibilities indicated no difference between cultures grown under NG and LSMMG conditions for all antibiotics, and the results indicated that the bacteria were equally susceptible. MICs determined using the broth microdilution method also indicated no difference in antibiotic susceptibility between LSMMG and NG cultures. The MICs against AM, GM, and NA were $1.0,0.5$, and $4.0 \mathrm{mg} / \mathrm{L}$, respectively.

\section{Bacterial Growth in the Presence and Absence of Sub-inhibitory Antibiotic Concentrations}

The growth curves of bacteria cultured in $\mathrm{MH}$ broth in the presence or absence of $1 / 2 \times \mathrm{MIC}$ antibiotic concentrations were plotted as a function of the optical density at $600 \mathrm{~nm}$ $\left(\mathrm{OD}_{600}\right)$ against time (Figure 2). The ODs of E. coli O157:H7

\footnotetext{
${ }^{1}$ http://rsbweb.nih.gov/ij/
} 


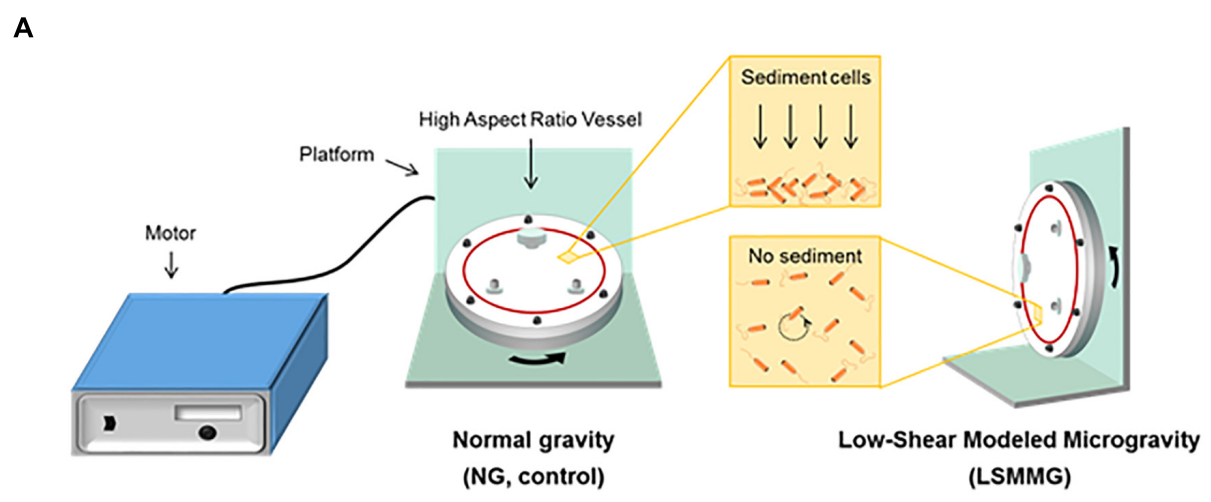

B

Conventional antibiotic susceptibility test:

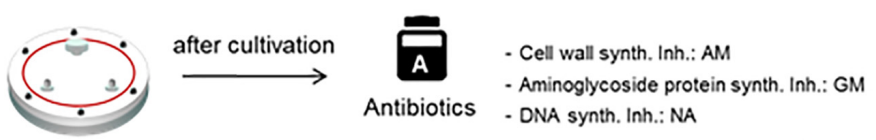

$\left.\begin{array}{l}\text { 1. Disk-diffusion method (using solid agar) } \\ \text { 2. MIC determination by broth microdilution assay }\end{array}\right\} \begin{gathered}\text { Unavoldable exposure } 101 \mathrm{G} \text { condition } \\ \text { during post-cultivation }\end{gathered}$

Novel approaches:

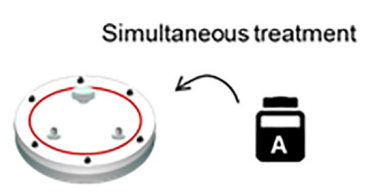

Real-time checking

Direct observation

1. Bacterial growth monitoring

1. Flow cytometry analysis $\downarrow$ Cell damage

2. Time-kill assay

2. Phase contrast microscopy $\downarrow$ Morphology

Mechanism studies

1. Real-time RT-PCR Stress and virulence-related genes

2. EtBr assay Efflux pump and cell permeability

FIGURE 1 | (A) The High-Aspect Ratio Vessel (HARV)-Rotary Cell Culture System used to generate simulated microgravity in ground-based investigations. (B) Schematic representations of a conventional antibiotic susceptibility test and novel approaches applied in the current study.

cultured for $48 \mathrm{~h}$ in $\mathrm{MH}$ broth only (antibiotic-free control) under different gravity conditions were significantly different (Figure 2A, LSMMG: $\mathrm{OD}_{600}$ 3.2; NG: $\mathrm{OD}_{600}$ 2.7; $P<0.05$ ). However, when E. coli O157:H7 was cultivated with NA under LSMMG and NG, bacterial growth was significantly lower than in the controls and the growth patterns under different gravity conditions were also significantly different at a particular time (Figure 2D, $P<0.05$ ). When cultivated with $\mathrm{NA}$ or GM (Figure 2C), the commencement of bacterial growth was not observed until after $6 \mathrm{~h}$ of incubation. ODs at $12 \mathrm{~h}$ were the lowest when grown in the presence of NA (LSMMG: $\mathrm{OD}_{600}$ 0.22; NG: OD600 0.08) compared with the other treatments (LSMMG: $\mathrm{OD}_{600}$ 0.6-2.2; NG: $\mathrm{OD}_{600}$ 0.5-2.2). The $\mathrm{OD}_{600}$ of strain ATCC 43895 with NA was significantly higher under LSMMG than NG at $24 \mathrm{~h}(P<0.05)$ and $48 \mathrm{~h}(P<0.001)$. High optical densities in the presence of NA were noted after $48 \mathrm{~h}$ of culture under LSMMG (LSMMG: $\mathrm{OD}_{600}$ 2.3; NG:
$\mathrm{OD}_{600}$ 1.4). Since no significant differences between LSMMG and NG cultures were apparent in the corresponding viable cell counts during bacterial growth (Figures 2A-D) differences in the optical density in the control and NA treated cultures under LSMMG were probably the result of changes in cell morphology (supportive observations of an increased cell size under LSMMG are presented in Supplementary Figure S1).

\section{Transcriptional Changes Elicited by Sub-inhibitory Concentrations of Antibiotics}

Alterations in the expression of genes in E. coli O157:H7 ATCC 43895 ( $24 \mathrm{~h}$ culture) were examined using the quantitative real-time polymerase chain reaction (qRT-PCR; the total RNA concentrations in the samples are shown in Figure 3A). The relative LSMMG/NG expression ratios of the stress-related 
A

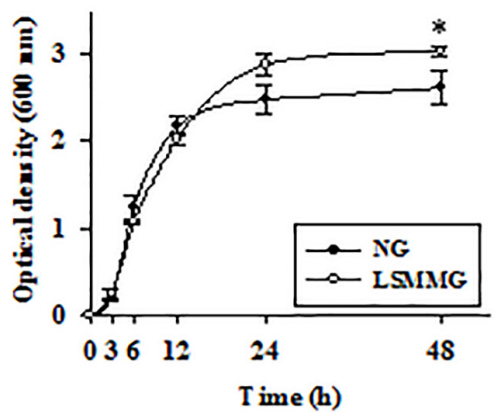

B

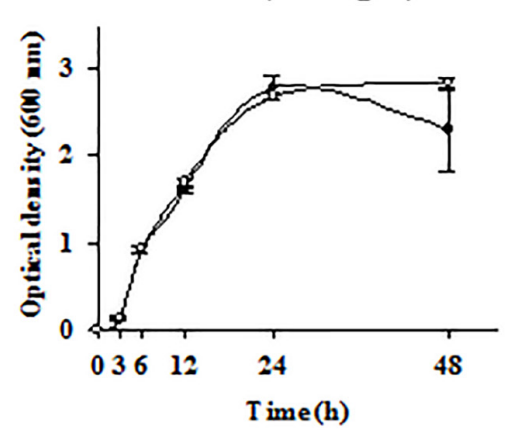

C

GMI (0.25 mg/L)

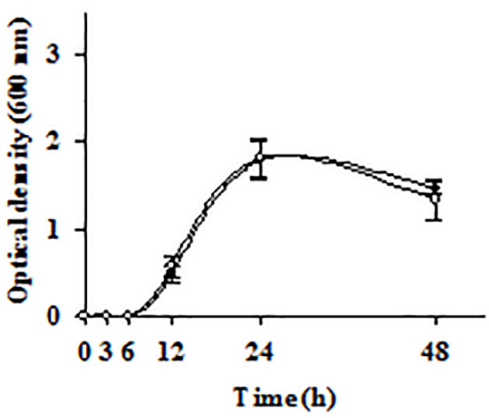

D

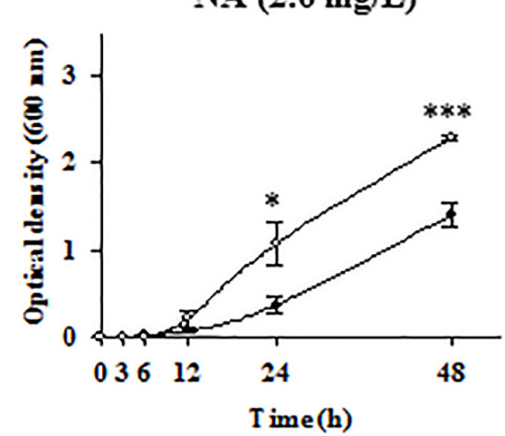

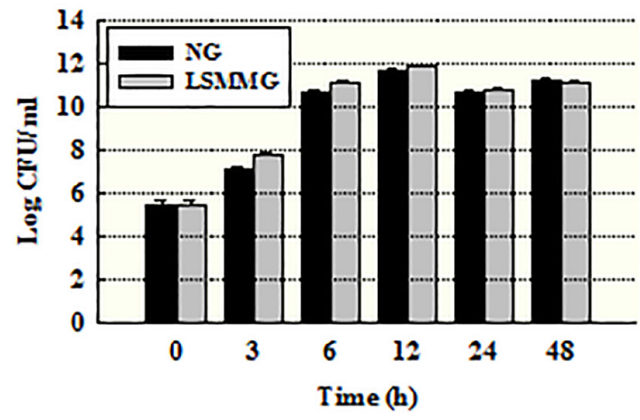
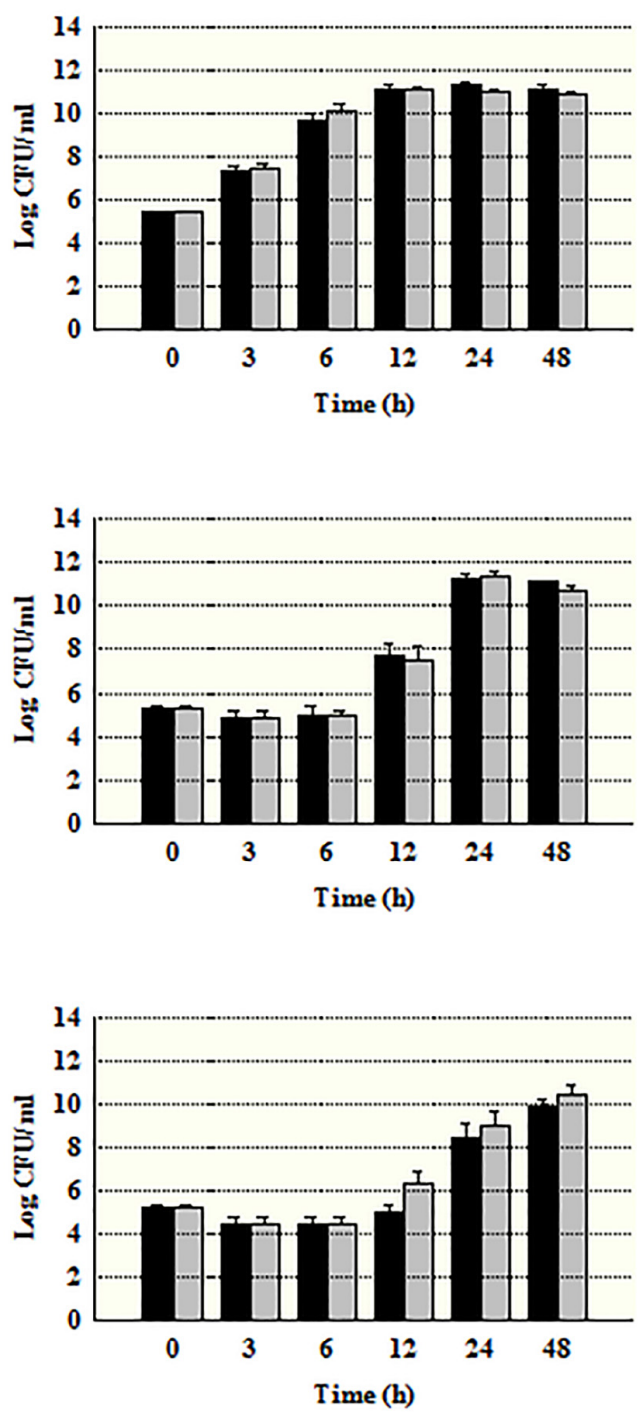

FIGURE 2 | Optical density at $600 \mathrm{~nm}$ and viable cell counts of Escherichia coli O157:H7 cultured under NG and LSMMG in (A) MH broth with no antibiotics, or with the sub-inhibitory antibiotic concentrations (1/2 $\times$ MIC); (B) $0.50 \mathrm{mg} / \mathrm{L}$ of AM; (C) $0.25 \mathrm{mg} / \mathrm{L}$ of GM; and (D) $2.0 \mathrm{mg} / \mathrm{L}$ of NA. The data are presented as the mean \pm standard error (SE) from 6 to 10 independent experiments. The asterisks represent significant differences between NG and LSMMG cultures $\left({ }^{*} P<0.05\right.$, *** $P<0.01$, and $\left.{ }^{* * *} P<0.001\right)$. 
A

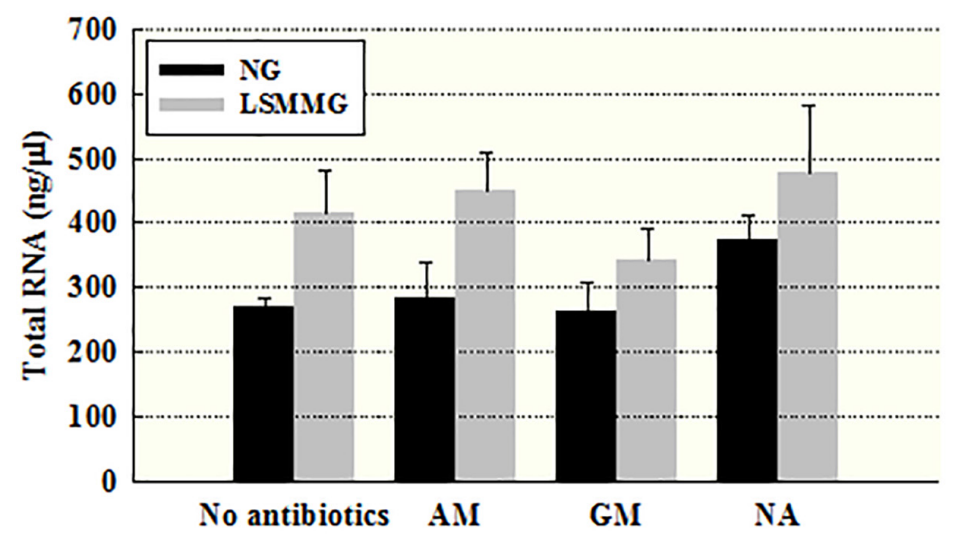

C

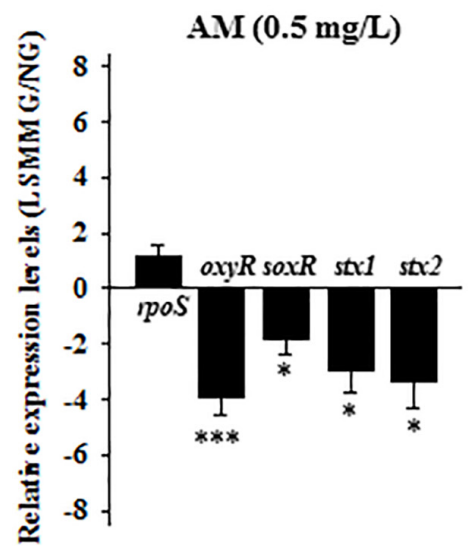

D

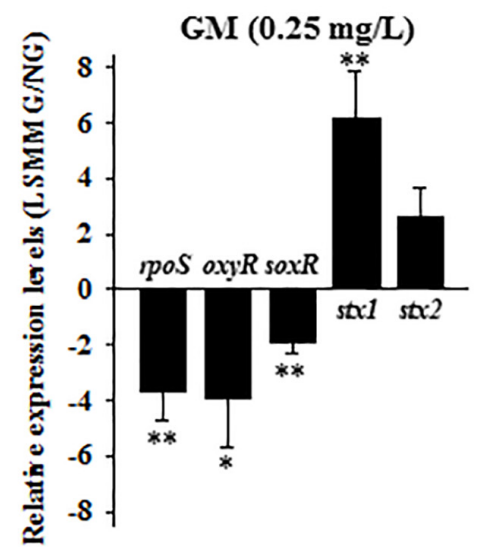

B

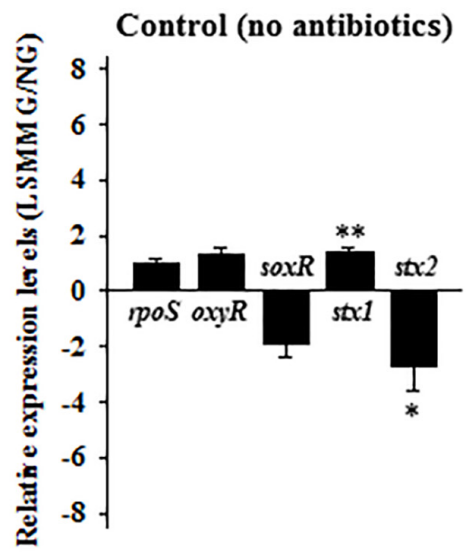

E

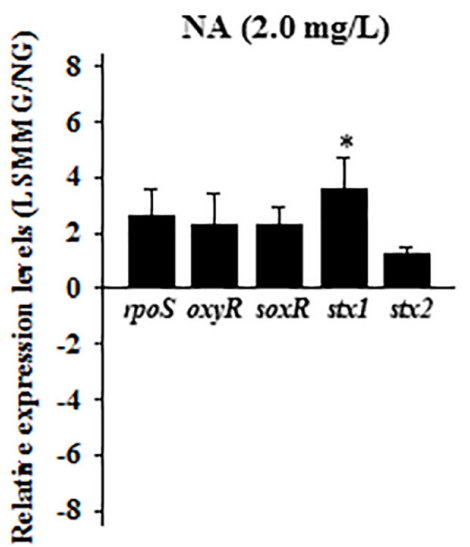

FIGURE 3 | (A) Total RNA concentrations $(\mathrm{ng} / \mu \mathrm{l})$, and the average relative expression of the stress or virulence-related genes in E. coli ATCC 43895 cells cultured under NG and LSMMG in (B) MH broth (no antibiotics) and in the presence of $1 / 2 \times$ MIC of (C) AM, (D) GM, and (E) NA for 24 h. The data are presented as the mean \pm standard error (SE) from six independent experiments. The asterisks represent significant differences between NG and LSMMG cultures $\left({ }^{*} P<0.05\right.$, $* * P<0.01$, and $* * * P<0.001)$.

genes (rpoS for general stress and $o x y R$ and $\operatorname{sox} R$ for oxidative stress) and virulence-related genes (stx 1 and st $x 2$ ) are shown in Figures 3B-E.

The expression of stress-related genes was not significantly changed (Figure 3B, $P>0.05$ ). However, marked differences in gene expression were noted when the bacterial cells were cultivated in the presence of sub-inhibitory concentrations of antibiotics. The expression of all stress-related genes tested was reduced under LSMMG in the presence of $1 / 2 \times$ MIC of AM (Figure 3C) and GM (Figure 3D), with average fold-changes of -1.8 to -3.9 , and -1.9 to -3.9 , respectively. The exception was rpoS expression under AM treatment $(P>0.05)$. For the NA treatment (Figure 3E), expression of $r p o S$, oxyR, and $s o x R$ tended to be up-regulated, but there was no significant difference $(P>0.05)$.

In the case of the toxin genes, the expression of stx 1 was upregulated (1.3-fold, $P<0.01)$ and the expression of stx 2 was down-regulated (2.8-fold, $P<0.05)$ in $\mathrm{MH}$ broth in the absence of antibiotics under LSMMG (Figure 3B). When cultivated in the presence of $\mathrm{AM}$, however, the expression of both toxin genes was significantly reduced under LSMMG conditions, from an average of 2.9- to 3.3-fold (Figure 3C, $P<0.05$ ). The GM and NA treatments induced significant increase of stx 1 expression under LSMMG conditions from 3.5- to 6.2-fold (Figures 3D,E), while there was no significant difference in the expression of st $x 2$ $(P>0.05)$.

\section{Time-Kill Assay Under LSMMG}

As shown in Figure 4A, rapid bactericidal effects were produced in the presence of all antibiotics at $4 \times \mathrm{MIC}$ after 3-6 h of exposure, but for the GM and NA treatments, bacterial regrowth was observed. When E. coli O157:H7 cells were treated with $\mathrm{AM}$ at $4 \mathrm{mg} / \mathrm{L}(4 \times \mathrm{MIC})$ and incubated under $\mathrm{NG}$, cell concentrations gradually decreased and no viable cells were detectable after $24 \mathrm{~h}$. By contrast, AM did not completely abolish the viability of cells under LSMMG after 24 and $48 \mathrm{~h}$ incubations, with 1.7 and $0.6 \log _{10} \mathrm{CFU} / \mathrm{ml}$ of cells surviving, respectively. GM was bactericidal at $2 \mathrm{mg} / \mathrm{L}$ after a $3 \mathrm{~h}$ incubation, but bacterial regrowth was observed after $3 \mathrm{~h}$ incubation under both gravity conditions. At the end of the incubation period (48 h), 
the microbial populations under LSMMG were significantly higher than under NG, with concentrations of 8.6 and 6.2 $\log _{10} \mathrm{CFU} / \mathrm{ml}$, respectively $(P<0.001)$. NA was bactericidal at $4 \times \operatorname{MIC}(16 \mathrm{mg} / \mathrm{L})$ after 3 and $6 \mathrm{~h}$ of incubation under both gravity conditions, and cells were no longer detectable from $12 \mathrm{~h}$ incubation under NG. However, cells cultivated under LSMMG grew after $6 \mathrm{~h}$ and showed significantly higher populations than those under NG $\left(1.9 \log _{10} \mathrm{CFU} / \mathrm{ml}\right.$ at $12 \mathrm{~h}, P<0.001 ; 3.2 \log _{10}$ $\mathrm{CFU} / \mathrm{ml}$ at $24 \mathrm{~h}, P<0.01 ; 4.0 \log _{10} \mathrm{CFU} / \mathrm{ml}$ at $\left.48 \mathrm{~h}, P<0.001\right)$.

\section{Flow Cytometry Analysis of Cellular Damages}

To understand the increased bacterial resistance to antibiotics under LSMMG, cellular damage after exposure to antibiotics was evaluated using flow cytometric analysis with Alexa Fluor 633 hydrazide (AFH), a dye that targets protein carbonylation (Saint-Ruf et al., 2016).

Antibiotic-treated and untreated E. coli O157:H7 ATCC 43895 cells cultured under NG and LSMMG were stained with AFH, and the changes in the distributions of fluorescent signal intensity were compared. Results are shown in Figures 4B,C (mean values from three independent experiments). The histograms reveal that, when compared with untreated cells, the fluorescent signal emitted by antibiotic-treated cells shifted to the M1 region, i.e., the samples contained more damaged, or more precisely carbonylated, cells. The carbonylated cells within the population of untreated E. coli O157:H7 cells cultured under LSMMG and NG represented only $1.9-3.6 \%$ of the total population, but this proportion increased to $28.9-86.8 \%$ after a 24 h treatment with $4 \times$ MIC of AM, GM, and NA. The AM treatment resulted in similar percentages of carbonylated cells under LSMMG and NG, with $80.5 \%$ for $1.7 \log _{10} \mathrm{CFU} / \mathrm{ml}$ in the LSMMG culture and $86.8 \%$ for no detectable cells in the NG culture, respectively (no significant difference, $P>0.05$ ). The GM and NA treatments, however, resulted in a lower degree of cell carbonylation under LSMMG than under NG. Only $28.9 \%$ of the GM-treated cells were damaged under LSMMG $\left(7.5 \log _{10} \mathrm{CFU} / \mathrm{ml}\right)$, while $44.2 \%$ of cells were damaged under NG $\left(6.2 \log _{10} \mathrm{CFU} / \mathrm{ml}\right)(P<0.05)$. The percentage of damaged cells treated with NA under LSMMG was $60.3 \%\left(3.4 \log _{10} \mathrm{CFU} / \mathrm{ml}\right)$, while that of cells under NG was $79.9 \%$ (ND, not detected) $(P<0.05)$.

\section{Efflux Pump Activity Under LSMMG}

EtBr was used to examine the effect of LSMMG on efflux pump activity and cell permeability. The fluorescent signal of extracellular EtBr is very low, but it is amplified once it enters the cell. The EtBr concentration that resulted in the highest fluorescence with no significant reduction of the initial cell concentration was determined to be $5.0 \mathrm{mg} / \mathrm{L}$ (Supplementary Figure S2). The results of the EtBr accumulation assay under simulated microgravity are shown in Figure 5. Under conditions where efflux was inhibited (CCCP $100 \mu \mathrm{M}$, no glucose at $25^{\circ} \mathrm{C}$ ), there was no significant difference in $\mathrm{EtBr}$ accumulation (measured using arbitrary fluorescence units) and cell populations between NG and LSMMG cultures (Figures $\mathbf{5 A}, \mathbf{C}$ ). The presence of $0.4 \%$ glucose in the medium resulted in the activation of the efflux pump at $37^{\circ} \mathrm{C}$ (optimal conditions), leading to a reduced accumulation of EtBr in both NG and LSMMG cultures (Figure 5B). The EtBr accumulation in cells under LSMMG was significantly lower than in cells under NG after a $6 \mathrm{~h}$ cultivation (NG: 10.8 units; LSMMG: 7.7 units; $P<0.001$ ). The accumulation of EtBr increased, and the fluorescence of LSMMG cultures was lower than that of NG cultures (NG: 19.5; LSMMG: 8.2; $P<0.001$ ), after prolonged exposure $(24 \mathrm{~h})$.

\section{Antibiotic-Elicited Morphological Changes}

Flow cytometric analysis of E. coli O157:H7 cells cultured under LSMMG and NG revealed that there were differences between them in the forward scatter (FSC)/side scatter (SSC) dot plot (Supplementary Figure S3). This suggests morphological differences in the cells. To determine whether antibiotic treatment under LSMMG induced changes in bacterial morphology when compared with NG, the morphology of E. coli O157:H7 ATCC 43895 cells was examined in the absence (control) or presence of the selected antibiotics (Figure 6).

Bacterial cells cultured in control MH broth under LSMMG were medium/long rods, whereas their NG counterparts were shorter and oval-shaped. The average cell length of cells in LSMMG cultures was significantly greater than in NG cultures (Figure 6A, NG: $1.1 \mu \mathrm{m}$; LSMMG: $2.2 \mu \mathrm{m}$; $P<0.001$ ). LSMMG cultures had higher FSC intensities than NG cultures with increased cell granularity (Supplementary Figure S3A, LSMMG: 14.8\%, NG: $23.9 \%$ in the M2 region). Treating E. coli O157:H7 with $4 \times$ MIC of AM caused the cells to become filamentous, and this effect was prominent in LSMMG cultures (Figure 6B, $P<0.001$ ). With respect to the filamentous cell size (ovalshaped cells were excluded from measurements), the cell length in LSMMG cultures ranged from 20.5 to $153.9 \mu \mathrm{m}$ (average: $57.4 \mu \mathrm{m}$ ), whereas cell length in NG cultures ranged from 7.7 to $43.6 \mu \mathrm{m}$ (average: $27.5 \mu \mathrm{m}$ ). Increased cell length was also apparent from FACS analysis, with the FSC intensity of LSMMG cultures in the M2 region being higher than that of NG cultures (Supplementary Figure S3B, LSMMG: 24.4\%, NG: $28.9 \%)$. However, in this case, oval-shaped cells were included from measurements. Treatment with GM did not induce cell filamentation since there was no significant difference in cell length between NG and LSMMG cultures (Figure 6C). NA treatment, however, induced morphological changes in cells grown under LSMMG and longer bacteria were frequently observed (Figure 6D, NG: $1.6 \mu \mathrm{m}$; LSMMG: $8.6 \mu \mathrm{m} ; P<0.001$ ).

\section{DISCUSSION}

Most antibiotic susceptibility studies with ground-based microgravity simulation performed to date have focused on measuring the MIC values for bacteria either in space (Tixador et al., 1985b) or after landing (Juergensmeyer et al., 1999). Although the MIC is the most widely used parameter for evaluating the efficacy of antibiotics, its main limitation is the lack of information on the rate of 
A
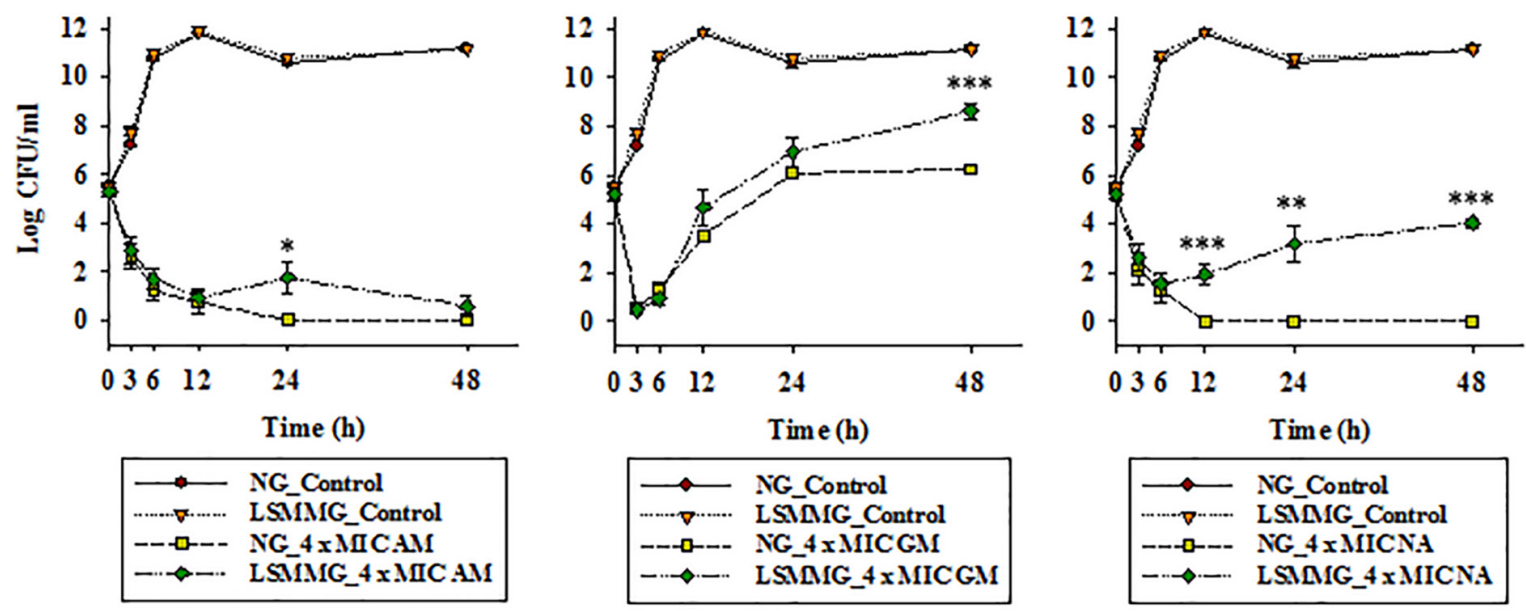

B

Control (no antibiotics)
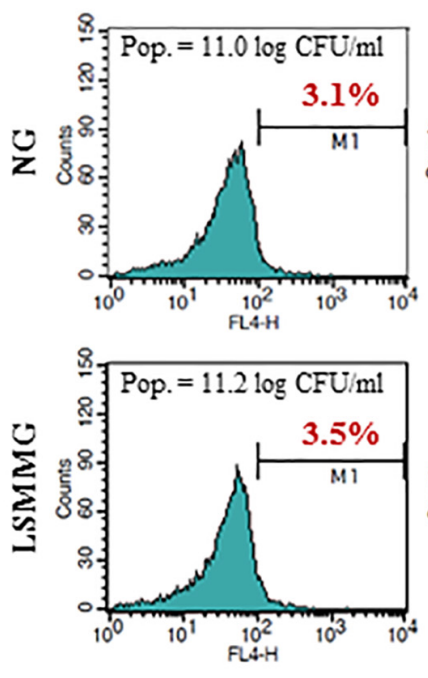

C

\begin{tabular}{|ccccc|}
\hline \multicolumn{5}{c|}{ Fluorescent signal within the Ml region, \% $(\log$ CFU/ml) } \\
\hline & Control (no antibiotics) & AM $(\mathbf{4 . 0} \mathbf{~ m g} / \mathbf{L})$ & GM $(\mathbf{2 . 0} \mathbf{~ m g} / \mathbf{L})$ & NA $(\mathbf{1 6 . 0} \mathbf{~ m g} / \mathbf{L})$ \\
\hline \multirow{2}{*}{ NG } & $1.9 \pm 0.7$ & $86.8 \pm 0.4$ & $44.2 \pm 2.4^{3}$ & $79.9 \pm 4.3^{\mathbf{3}}$ \\
& $(11.0 \pm 0.1)$ & $(\mathrm{ND})$ & $(6.2 \pm 0.3)$ & $(\mathrm{ND})$ \\
\hline \multirow{2}{*}{ LSMMG } & $3.6 \pm 1.2$ & $80.5 \pm 4.0$ & $28.9 \pm 2.2^{\circ}$ & $60.3 \pm 3.5^{\circ}$ \\
& $(11.4 \pm 0.1)$ & $(1.7 \pm 0.9)$ & $(7.5 \pm 0.3)$ & $(3.4 \pm 0.4)$ \\
\hline
\end{tabular}

Data represent mean $\pm S E$ from three independent experiments.

$a$ and $b$ represent significant differences between NG and LSMMG cultures $(P<0.05)$.

FIGURE 4 | (A) Time-kill curve analysis of AM, GM, and NA under NG and LSMMG for E. coli O157 ATCC 43895 in MH broth. e, growth control under NG; $\nabla$, growth control under LSMMG; antibiotics at 1/2 $\times$ MIC under NG; at $4 \times$ MIC under LSMMG. The data are presented as the mean \pm standard error (SE) from six independent experiments. The asterisks represent significant differences between NG and LSMMG cultures $\left({ }^{*} P<0.05\right.$, ${ }^{* *} P<0.01$, and ${ }^{* * *} P<0.001$ ). (B,C) Flow cytometry analysis of E. coli O157:H7 ATCC 43895 treated, or not, with $4 \times$ MIC of AM, GM, and NA under NG and LSMMG, for $24 \mathrm{~h}$ in MH broth: (B) histogram of fluorescent signal and (C) average fluorescent signal within the $\mathrm{M} 1$ region (\%). 

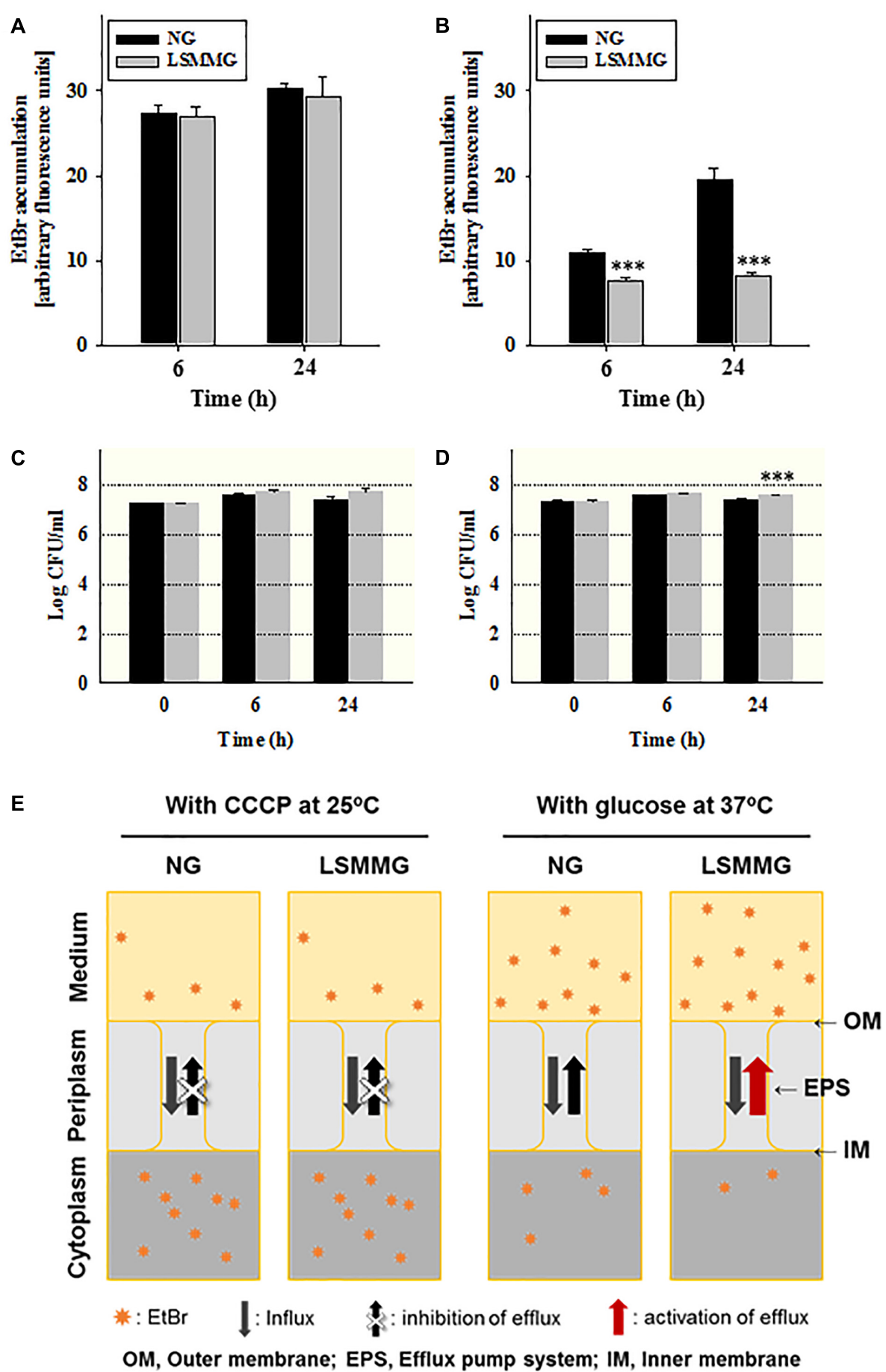

FIGURE 5 | EtBr accumulation in E. coli O157:H7 ATCC 43895 cells cultured under NG and LSMMG for $24 \mathrm{~h}$ in (A) the presence of $100 \mu \mathrm{M} \mathrm{CCCP}$ at $25^{\circ} \mathrm{C}$ and (B) the presence of $0.4 \%$ glucose at $37^{\circ} \mathrm{C}$. (C,D) Viable cell counts after each treatment from $(\mathbf{A}, \mathbf{B})$, respectively. The data are presented as the mean \pm standard error (SE) from six independent experiments. The asterisks represent significant differences between NG and LSMMG cultures ( $^{*} P<0.05$, ** $P<0.01$, and $* * * P<0.001)$. (E) A schematic representation of EtBr efflux under NG and LSMMG.

the antibacterial effect (Mueller et al., 2004). To test the antibiotic efficacy under microgravity more accurately on Earth, novel approaches to determine the activities of antibiotics are needed.
The antibiotic susceptibility of E. coli O157:H7 cells that had been cultivated under LSMMG was first tested using conventional disk diffusion and MIC determination methods (Table 1), which revealed no differences between the 

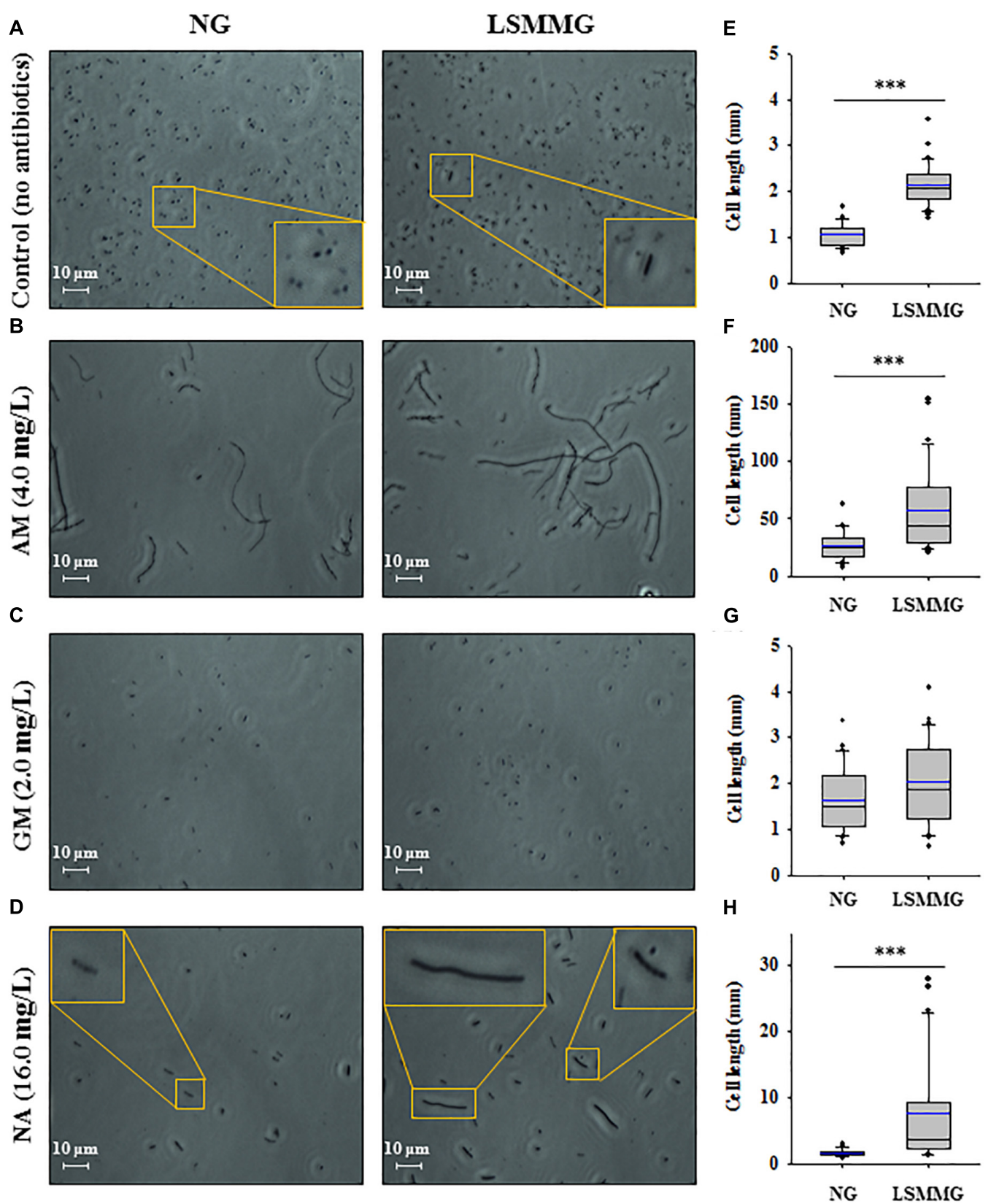

FIGURE 6 | (A-D) The liquid cultures of strain ATCC 43895 in the absence (control) or presence of antibiotics (at $4 \times$ MIC) were centrifuged to concentrate the residual biomass; the wet mount preparations were then analyzed using phase-contrast microscopy. Scale bar: $10 \mu \mathrm{m}$. (E-H) Cell lengths in bacterial cultures in (A-D), respectively. The squares indicate the interquartile range for each data point, and the black and blue lines denote the median and mean values, respectively. The error bars above and below the squares indicate the $90^{\text {th }}$ and $10^{\text {th }}$ percentiles, respectively, and the black circles represent the outliers. The asterisks represent significant differences between NG and LSMMG cultures $\left({ }^{*} P<0.05\right.$ and $\left.{ }^{* * *} P<0.001\right)$.

LSMMG and NG cultures. Previous studies have shown no alterations in antibiotic sensitivity of post-LSMMG cultures (Kacena and Todd, 1999; Tucker et al., 2007). However, some studies have reported that antibiotics are less effective in suspension cultures in comparison to solid agar surface cultures in the space environment, and that these traits are not retained following a spaceflight (Lapchine et al., 1986, 1987; Tixador et al., 1994). These previous reports support the current observations by conventional antibiotic susceptibility tests. The antibiotic susceptibility tests suggested that ground-based studies on antibiotic efficacy should be performed in liquid cultures under LSMMG conditions. The current study used alternative methods for the evaluation of antibiotic efficacy, i.e., a real-time growth-monitoring and a time-kill assay (Mueller et al., 2004), and their advantage over the standard MIC approach lies mainly in enabling 
time-dependent measurements in liquid culture under LSMMG (Figure 1).

Unlike the results of conventional antibiotic susceptibility testing, significant differences for some antibiotics were apparent in the time-dependent growth (Figure 2) and killing (Figure 4) data. Although bacterial growth (measured by optical density) was greater in LSMMG cultures than in NG cultures after $48 \mathrm{~h}$ in the antibiotic-free control samples (Figure 2A), no significant differences in growth were apparent between LSMMG and NG cultures exposed to $1 / 2 \times$ MICs of AM and GM (Figures 2B,C, $P>0.05)$. By contrast, the optical densities of $E$. coli O157:H7 cultures were significantly higher under LSMMG than under NG after 24 and $48 \mathrm{~h}$ incubation in the presence of NA (Figure 2D, $P<0.05$ and $P<0.001$, respectively). The mechanisms behind these effects at sub-inhibitory antibiotic concentrations under LSMMG could be explained as follows: when bacteria are exposed to antibiotics during cell division, the drugs can readily bind to the target, leading to no significant differences in cell mass between LSMMG and NG cultures, but in the case of NA treatment, it is hypothesized that other genetic differences explain the observations.

The bacterial general stress response, regulated by $\sigma^{\mathrm{s}}$ (the product of the rpoS gene), is responsible for bacterial resistance to antibiotics because it results in the expression of core proteins that protect such biomolecules as the cell wall, proteins, and DNA (Matin, 2009). As bactericidal antibiotics damage these molecules, $\sigma^{\mathrm{S}}$ is likely to have played a role in protecting bacteria against the antibiotics used here. Indeed, a previous study reported increased translational efficiency of rpoS in generic E. coli under LSMMG conditions (Lynch et al., 2004). Bactericidal antibiotics also induce the production of reactive oxygen species (ROS) by activating the tricarboxylic acid cycle (Lobritz et al., 2015). The $\operatorname{oxy} R$ and $\operatorname{soxR}$ genes are oxidative stress-related genes that counter the challenges posed by ROS (Lushchak, 2001). These stress-related genes were all down-regulated (1.8to 3.9-fold) in LSMMG cultures cultivated with $1 / 2 \times$ MIC AM and GM showing no significant difference in optical densities when compared to corresponding NG cultures, except for rpoS expression in AM treatment $(P>0.05$; Figures 3C,D). In the case of NA treatment, however, rpoS, oxyR, and soxR tended to be up-regulated (3.1- and 2.7-fold, respectively), which supports the observation of bacterial growth in the presence of sub-inhibitory concentrations of NA under LSMMG.

Previous studies have reported increased virulence of pathogenic E. coli under LSMMG, for example, increased intimin production in enterohemorrhagic E. coli, increased expression of heat labile enterotoxin in enterotoxigenic E. coli, and increased adherence of adherent-invasive E. coli (Carvalho et al., 2005; Chopra et al., 2006; Allen et al., 2008). The ability to produce Shiga toxin, encoded by the stx genes, is the key virulence trait of E. coli O157:H7. Here, stx1 was up-regulated while stx2 was down-regulated in bacterial cells cultured in the absence of antibiotics under LSMMG (Figure 3B). Unlike the AM treatment, exposure to GM induced the up-regulation of stx 1 (6.2-fold, $P<0.01)$ and NA also induced the up-regulation of stx1 (3.5-fold, $P<0.05$ ), suggesting that GM and NA might not be appropriate therapeutic choices against this strain of E. coli
O157:H7 under microgravity (Figures 3C-E). Since the current results have identified potential risks in using inappropriate antibiotics against the Shiga toxin-producing E. coli O157:H7 during spaceflight, a thorough examination of antibiotic use (i.e., their type, amounts, side effects, etc.) in space should be conducted both in vitro and in vivo.

Unlike the observations of bacterial growth in the presence of sub-inhibitory antibiotic concentrations, the time-kill assay revealed a significantly higher viability of LSMMG cultured cells than NG cultured cells in the presence of the tested antibiotics, i.e., a reduced antibiotic efficacy under LSMMG (Figure 4). Viable cell counts were higher under LSMMG than under NG in response to $4 \times$ MIC of AM and GM at $24 \mathrm{~h}(P<0.05)$ and $48 \mathrm{~h}$ $(P<0.001)$, respectively (Figure $4 \mathrm{~A})$. These trends were more obvious during exposure to NA where regrowth was observed under LSMMG after $6 \mathrm{~h}$, while no bacteria were detected from $12 \mathrm{~h}$ onwards under NG.

To gain further insight into the mechanism of the increased bacterial resistance to antibiotics under the simulated microgravity, the degree of cellular damage after exposure to antibiotics was evaluated by flow cytometry using AFH, a dye that targets protein carbonylation (Saint-Ruf et al., 2016). Antibiotic efficacy is linked to bacterial cellular respiration (Lobritz et al., 2015). ROS generated by antibiotics damages the proteins in bacterial cells by, for example, irreversible protein carbonylation. Thus, determination of the extent of carbonylation of antibiotic-treated cells can be used as a marker of impaired cell viability and an indirect measure of ROS generation. The degree of protein carbonylation elicited in E. coli O157:H7 ATCC 43895 cells by GM and NA treatment was lower under LSMMG than under NG (Figures 4B,C). Treatment with $\mathrm{AM}$, resulting in small differences in viable cell counts under LSMMG and NG, also resulted in small differences in the degree of carbonylation $(P>0.05)$. This might be because the main target of AM is the cell wall, the outermost protection system of bacteria, while GM and NA have to penetrate the cell envelopes to reach their targets in the cytoplasm. It is hypothesized that the concentration of AM molecules at the cell wall might not be significantly different between LSMMG and NG cultures. However, the degree of carbonylation, and hence damage, associated with GM and NA treatments under LSMMG was significantly lower than under NG.

Penetration and efflux of antibiotics are a significant matter for antibiotic efficacy (Miller, 2016). The possibility that an efflux pump is activated under simulated microgravity conditions resulting in an increased efflux of antibiotic molecules was investigated by measuring the accumulation of $\mathrm{EtBr}$ and its extrusion from E. coli O157:H7 cells, a result of the balance between the molecule's entry (influx) and the extruding activity of the efflux pump (Viveiros et al., 2007). To test the permeability of bacterial cells under LSMMG and NG, EtBr accumulation was observed under conditions inhibitory for efflux (i.e., in the presence of CCCP). There was no significant difference in $\mathrm{EtBr}$ accumulation between LSMMG and NG cultures (Figure 5A, $P>0.05)$, indicating that efflux-independent cell permeability was not affected under LSMMG. However, the fluorescent intensity of the LSMMG culture was significantly lower than 
that of the NG culture (about twofold) in the presence of $0.4 \%$ glucose after $24 \mathrm{~h}$, suggesting that less EtBr accumulated inside the cells because of a more activate efflux pump under LSMMG (Figures 5B,E). A previous report presented results demonstrating that the expression of efflux pump genes ( $a c r A B$ and tolC) is up-regulated in E. coli ATCC 25922 under simulated microgravity (Xu et al., 2015).

It was also found that the growth of E. coli O157:H7 in a medium containing $4 \times \mathrm{MIC}$ of $\mathrm{AM}$, a $\beta$-lactam antibiotic, under LSMMG resulted in more pronounced cell filamentation and septation than under NG (Figure 6). Various stresses, including exposure to $\beta$-lactam antibiotics, DNA damage, and high hydrostatic pressure (Pratt et al., 2012; Yadavalli et al., 2016), cause filamentation of $E$. coli. Although the protective effect of cellular filamentation in the context of antibiotic tolerance has not been established, some evidence exists that filamentation improves cell survival under various stresses. The control of cell division by a cell, as observed by us in the form of a division block, is generally assumed to enhance cell fitness under stress (Yadavalli et al., 2016). Though the cell damages measured by AFH were not significantly different between LSMMG and NG cultures in the current study, the degree of carbonylation of the cells tended to be reduced in LSMMG cultures (Figure 4B). This supports the significantly higher populations of LSMMG cultures at $24 \mathrm{~h}$ in the presence of AM (Figure 4A, $P<0.05$ ). Taken together, these observations suggest that $E$. coli $\mathrm{O} 157: \mathrm{H} 7$ cells may try to maximize the chance of survival in the presence of antibiotics in response to LSMMG.

Here, an extensive analysis of in vitro antibiotic efficacy against Shiga toxin-producing E. coli O157:H7 cells under simulated microgravity was conducted to explore potential undesirable pharmacological effects during spaceflight. Of the three different antibiotics tested, sub-inhibitory concentrations of NA induced more active growth in LSMMG cultures than in NG cultures, with an accompanying increased expression of Shiga toxin genes. Previous studies have reported the virulence and susceptibility to antibiotics of bacteria under microgravity (Nickerson et al., 2000; Lawal et al., 2013), but, to the best of our knowledge, this is the first report describing the possibility that exposure of E. coli O157:H7 to inappropriate

\section{REFERENCES}

Allen, C. A., Niesel, D. W., and Torres, A. G. (2008). The effects of low-shear stress on adherent-invasive Escherichia coli. Environ. Microbiol. 10, 1512-1525. doi: $10.1111 / \mathrm{j} .1462-2920.2008 .01567 . \mathrm{x}$

Ball, J. R., and Evans, C. H. Jr. (2001). Safe Passage: Astronaut Care for Exploration Missions. Washington, DC: National Academies Press.

Bürk, C., Dietrich, R., Açar, G., Moravek, M., Bülte, M., and Märtlbauer, E. (2003). Identification and characterization of a new variant of Shiga toxin 1 in Escherichia coli ONT:H19 of bovine origin. J. Clin. Microbiol. 41, 2106-2112. doi: 10.1128/JCM.41.5.2106-2112.2003

Carvalho, H. M., Teel, L. D., Goping, G., and O'brien, A. D. (2005). A threedimensional tissue culture model for the study of attach and efface lesion formation by enteropathogenic and enterohaemorrhagic Escherichia coli. Cell. Microbiol. 7, 1771-1781. doi: 10.1111/j.1462-5822.2004.00594.x

Chopra, V., Fadl, A., Sha, J., Chopra, S., Galindo, C., and Chopra, A. (2006). Alterations in the virulence potential of enteric pathogens and bacterial-host antibiotics could induce toxin production. Bactericidal effects of antibiotics were reduced under LSMMG, with decreased protein carbonylation of cells, suggesting that reduced ROS generation and increased filamentation enhanced cell fitness and counteracted antibiotic stress. Since efflux pumps are thought to play important roles in antibiotic resistance, efflux pump inhibitors might be considered to be useful for treating bacterial infections, but further studies evaluating their effects are needed. This paper presents novel approaches for studying antimicrobial efficacy under simulated microgravity, and the results could help choose the effective therapeutic choices during a space mission.

\section{AUTHOR CONTRIBUTIONS}

HK and MR conceived the experiments. HK performed experiments, analyzed the data, and wrote the manuscript. MR supervised all research.

\section{FUNDING}

This research was supported by the Korea Research Foundation (NRF-2016R1A2B2012743) and Korea University Grant.

\section{ACKNOWLEDGMENTS}

The authors thank the School of Life Sciences and Biotechnology of the Korea University for BK 21 PLUS, and the Institute of Biomedical Science and Food Safety, Korea University Food Safety Hall, for enabling access to their equipment and facilities.

\section{SUPPLEMENTARY MATERIAL}

The Supplementary Material for this article can be found online at: https://www.frontiersin.org/articles/10.3389/fmicb. 2018.03214/full\#supplementary-material

cell interactions under simulated microgravity conditions. J. Toxicol. Environ. Health A 69, 1345-1370. doi: 10.1080/15287390500361792

CLSI (2012). Performance Standards for Antimicrobial Susceptibility Testing; Twenty-Second Informational Supplement. CLSI/NCCLS Document M100-S22. Wayne, PA: Clinical and Laboratory Standards Institute.

Crabbé, A., Schurr, M. J., Monsieurs, P., Morici, L., Schurr, J., Wilson, J. W., et al. (2011). Transcriptional and proteomic responses of Pseudomonas aeruginosa PAO1 to spaceflight conditions involve $\mathrm{Hfq}$ regulation and reveal a role for oxygen. Appl. Environ. Microbiol. 77, 1221-1230. doi: 10.1128/AEM.01582-10

Crucian, B., Stowe, R., Pierson, D., and Sams, C. (2008). Immune system dysregulation following short-vs long-duration spaceflight. Aviat. Space Environ. Med. 79, 835-843. doi: 10.3357/ASEM.2276.2008

Decelle, J., and Taylor, G. (1976). Autoflora in the upper respiratory tract of Apollo astronauts. Appl. Environ. Microbiol. 32, 659-665.

Ilyin, V. (2005). Microbiological status of cosmonauts during orbital spaceflights on Salyut and Mir orbital stations. Acta Astronaut. 56, 839-850. doi: 10.1016/j. actaastro.2005.01.009 
Juergensmeyer, M., Juergensmeyer, E., and Guikema, J. (1999). Long-term exposure to spaceflight conditions affects bacterial response to antibiotics. Microgravity Sci. Technol. 12, 41-47.

Kacena, M., and Todd, P. (1999). Gentamicin: effect on E. coli in space. Microgravity Sci. Technol. 12, 135-137.

Kim, H., Matin, A., and Rhee, M. (2014). Microgravity alters the physiological characteristics of Escherichia coli O157: H7 ATCC 35150, ATCC 43889, and ATCC 43895 under different nutrient conditions. Appl. Environ. Microbiol. 80, 2270-2278. doi: 10.1128/AEM.04037-13

Kim, H., and Rhee, M. (2016). Influence of low-shear modeled microgravity on heat resistance, membrane fatty acid composition, and heat stress-related gene expression in Escherichia coli O157:H7 ATCC 35150, ATCC 43889, ATCC 43890, and ATCC 43895. Appl. Environ. Microbiol. 82, 2893-2901. doi: 10.1128/ AEM.00050-16

Kimmitt, P. T., Harwood, C. R., and Barer, M. R. (2000). Toxin gene expression by shiga toxin-producing Escherichia coli: the role of antibiotics and the bacterial SOS response. Emerg. Infect. Dis. 6, 458-465. doi: 10.3201/eid0605.000503

Lapchine, L., Moatti, N., Gasset, G., Richoilley, G., Templier, J., and Tixador, R. (1986). Antibiotic activity in space. Drugs Exp. Clin. Res. 12, 933-938.

Lapchine, L., Moatti, N., Richoilley, G., Templier, J., Gasset, G., and Tixador, R. (1987). "Antibiotic activity in space, results and hypothesis," in Proceedings of the 3rd European Symposium on Life Sciences Research in Space SEE N 88-19893 12-51 (Paris: European Space Agency), 305-306.

Lawal, A., Kirtley, M. L., Van Lier, C. J., Erova, T. E., Kozlova, E. V., Sha, J., et al. (2013). The effects of modeled microgravity on growth kinetics, antibiotic susceptibility, cold growth, and the virulence potential of a Yersinia pestis ymoA-deficient mutant and its isogenic parental strain. Astrobiology 13, 821-832. doi: 10.1089/ast.2013.0968

Lobritz, M. A., Belenky, P., Porter, C. B., Gutierrez, A., Yang, J. H., Schwarz, E. G., et al. (2015). Antibiotic efficacy is linked to bacterial cellular respiration. Proc. Natl. Acad. Sci. U.S.A. 112, 8173-8180. doi: 10.1073/pnas.1509743112

Lushchak, V. (2001). Oxidative stress and mechanisms of protection against it in bacteria. Biochemistry 66, 476-489.

Lynch, S., Brodie, E., and Matin, A. (2004). Role and regulation of $\sigma$ s in general resistance conferred by low-shear simulated microgravity in Escherichia coli. J. Bacteriol. 186, 8207-8212. doi: 10.1128/JB.186.24.8207-8212.2004

Matin, A. (2009). "Stress, bacterial: general and specific", in Encyclopedia of Microbiology, 3rd Edn, ed. M. Schaechter (Oxford: Academic Press), 485-500. doi: 10.1016/B978-012373944-5.00102-4

Miller, S. I. (2016). Antibiotic resistance and regulation of the gram-negative bacterial outer membrane barrier by host innate immune molecules. mBio 7:e1541-16. doi: 10.1128/mBio.01541-16

Mueller, M., De La Peña, A., and Derendorf, H. (2004). Issues in pharmacokinetics and pharmacodynamics of anti-infective agents: kill curves versus MIC. Antimicrob. Agents Chemother. 48, 369-377. doi: 10.1128/AAC.48.2.369-377. 2004

Nickerson, C., Ott, C., Mister, S., Morrow, B., Burns-Keliher, L., and Pierson, D. L. (2000). Microgravity as a novel environmental signal affecting Salmonella enterica serovar Typhimurium virulence. Infect. Immunol. 68, 3147-3152. doi: 10.1128/IAI.68.6.3147-3152.2000

Nickerson, C. A., Ott, C. M., Wilson, J. W., Ramamurthy, R., and Pierson, D. L. (2004). Microbial responses to microgravity and other low-shear environments. Microbiol. Mol. Bio. Rev. 68, 345-361. doi: 10.1128/MMBR.68.2.345-361.2004

Phillips, C. A. (1999). The epidemiology, detection and control of Escherichia coli O157. J. Sci. Food Agric. 79, 1367-1381. doi: 10.1002/(SICI)1097-0010(199908) 79:11<1367::AID-JSFA374>3.0.CO;2-S

Pratt, Z. L., Chen, B., Czuprynski, C. J., Wong, A. C., and Kaspar, C. W. (2012). Characterization of osmotically induced filaments of Salmonella enterica. Appl. Environ. Microbiol. 78, 6704-6713. doi: 10.1128/AEM.01784-12

Riley, L. W., Remis, R. S., Helgerson, S. D., Mcgee, H. B., Wells, J. G., Davis, B. R., et al. (1983). Hemorrhagic colitis associated with a rare Escherichia coli serotype. New Engl. J. Med. 308, 681-685. doi: 10.1056/NEJM198303243081203

Saint-Ruf, C., Crussard, S., Franceschi, C., Orenga, S., Ouattara, J., Ramjeet, M., et al. (2016). Antibiotic susceptibility testing of the gram-negative bacteria based on flow cytometry. Front. Microbiol. 7:1121. doi: 10.3389/fmicb.2016. 01121
Schmittgen, T. D., and Livak, K. J. (2008). Analyzing real-time PCR data by the comparative CT method. Nat. Protoc. 3, 1101-1108. doi: 10.1038/nprot.2008.73

Schroeder, C. M., Zhao, C., Debroy, C., Torcolini, J., Zhao, S., White, D. G., et al. (2002). Antimicrobial resistance of Escherichia coli O157 isolated from humans, cattle, swine, and food. Appl. Environ. Microbiol. 68, 576-581. doi: 10.1128/AEM.68.2.576-581.2002

Schumacher, A., Trittler, R., Bohnert, J. A., Kümmerer, K., and Kern, W. V. (2007). Intracellular accumulation of linezolid in Escherichia coli, Citrobacter freundii and Enterobacter aerogenes: role of enhanced efflux pump activity and inactivation. J. Antimicrob. Chemother. 59, 1261-1264. doi: 10.1093/jac/dkl380

Smith, H. E., and Blair, J. M. (2013). Redundancy in the periplasmic adaptor proteins AcrA and AcrE provides resilience and an ability to export substrates of multidrug efflux. J. Antimicrob. Chemother. 69, 982-987. doi: 10.1093/jac/ $\mathrm{dkt} 481$

Taylor, G. R. (1974). Recovery of medically important microorganisms from Apollo astronauts. Aerosp. Med. 45, 824-828.

Taylor, P. W., and Sommer, A. P. (2005). Towards rational treatment of bacterial infections during extended space travel. Int. J. Antimicrob. Agents 26, 183-187. doi: 10.1016/j.ijantimicag.2005.06.002

Tietze, K. J., and Putcha, L. (1994). Factors affecting drug bioavailability in space. J. Clin. Pharmacol. 34, 671-676. doi: 10.1002/j.1552-4604.1994.tb02022.x

Tixador, R., Gasset, G., Eche, B., Moatti, N., Lapchine, L., Woldringh, C., et al. (1994). Behavior of bacteria and antibiotics under space conditions. Aviat. Space Environ. Med. 65, 551-556.

Tixador, R., Richoilley, G., Gasset, G., Planel, H., Moatti, N., Lapchine, L., et al. (1985a). Preliminary results of Cytos 2 experiment. Acta Astronaut. 12, 131-134.

Tixador, R., Richoilley, G., Gasset, G., Templier, J., Bes, J., Moatti, N., et al. (1985b). Study of minimal inhibitory concentration of antibiotics on bacteria cultivated in vitro in space (Cytos 2 experiment). Aviat. Space Environ. Med. 56, 748-751.

Tucker, D. L., Ott, C. M., Huff, S., Fofanov, Y., Pierson, D. L., Willson, R. C., et al. (2007). Characterization of Escherichia coli MG1655 grown in a low-shear modeled microgravity environment. BMC Microbiol. 7:15. doi: 10.1186/14712180-7-15

Valluri, J. V., and Gonda, S. R. (2006). Microgravity bioreactor systems for production of bioactive compounds and biological macromolecules. U.S. Patent No US11635785. Huntington, WV: Marshall University Research Corp.

Viveiros, M., Dupont, M., Rodrigues, L., Couto, I., Davin-Regli, A., Martins, M., et al. (2007). Antibiotic stress, genetic response and altered permeability of E. coli. PLoS One 2:e365. doi: 10.1371/journal.pone.0000365

Watts, J. L., Shryock, T. R., Apley, M., Bade, D. J., Brown, S. D., and Gray, J. T. (2008). Performance Standards for Antimicrobial Disk and Dilution Susceptibility Tests for Bacteria Isolated From Animals: Approved Standard. Wayne, PA: National Committee for Clinical Laboratory Standards.

Wilson, J., Ott, C., Zu Bentrup, K. H., Ramamurthy, R., Quick, L., Porwollik, S., et al. (2007). Space flight alters bacterial gene expression and virulence and reveals a role for global regulator Hfq. Proc. Natl. Acad. Sci. U.S.A. 104, 16299-16304. doi: 10.1073/pnas.0707155104

Xu, B., Li, C., Zheng, Y., Si, S., Shi, Y., Huang, Y., et al. (2015). Simulated microgravity affects ciprofloxacin susceptibility and expression of acrAB-tolC genes in E. coli ATCC25922. Int. J. Clin. Exp. Pathol. 8, 7945-7952.

Yadavalli, S. S., Carey, J. N., Leibman, R. S., Chen, A. I., Stern, A. M., Roggiani, M., et al. (2016). Antimicrobial peptides trigger a division block in Escherichia coli through stimulation of a signalling system. Nat. Commun. 7:12340. doi: $10.1038 /$ ncomms 12340

Conflict of Interest Statement: The authors declare that the research was conducted in the absence of any commercial or financial relationships that could be construed as a potential conflict of interest.

Copyright $\odot 2018$ Kim and Rhee. This is an open-access article distributed under the terms of the Creative Commons Attribution License (CC BY). The use, distribution or reproduction in other forums is permitted, provided the original author(s) and the copyright owner(s) are credited and that the original publication in this journal is cited, in accordance with accepted academic practice. No use, distribution or reproduction is permitted which does not comply with these terms. 